Original Article

\title{
The best body spot to detect the vital capacity from the respiratory movement data obtained by the wearable strain sensor
}

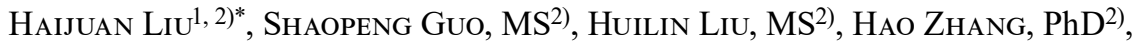 \\ Sujie Chen, PhD ${ }^{3)}$, Tsugumi Kuramoto-Ahuja, PT, MA ${ }^{1)}$, Tamae Sato, PT, MS ${ }^{1)}$, \\ Junichiro Kaneko, PT, PhD ${ }^{1)}$, Ko Onoda, PT, PhD ${ }^{1)}$, Hitoshi Maruyama, PT, PhD $^{1)}$ \\ 1) Department of Physical Therapy, International University of Health and Welfare: \\ 2600-1 Kitakanemaru, Ohtawara City, Tochigi 324-8501, Japan \\ 2) China Rehabilitation Research Center, China \\ 3) Shanghai Jiao Tong University, China
}

\begin{abstract}
Purpose] The purpose of this study is to find the best body spots on the chest and abdomen wall to obtain the correlated indicators to the vital capacity. [Subjects and Methods] Thirty healthy male staff of the center served as the participants were advised to conduct a breathing movement using spirometer and a wearable strain sensor (WSS) respectively, which was the measured at four spots on chest and abdomen wall from maximal end of inspiration to maximal end of expiration. The Pearson's correlation analysis was conducted to find the correlation of the data obtained respectively by the WSS and spirometer. [Results] The correlation of the mobility data at the four body spots to the vital capacity data were calculated for each level by means of Pearson's correlation coefficient, which showed that the values at each body spot were positive significant correlations and the highest value was at the 10th rib. [Conclusion] There was a correlation between the mobility data of the chest and abdomen obtained by the WSS and the vital capacity data obtained by the spirometer, for which, the 10th rib is the best body spot to detect the positive significant correlation.

Key words: Correlation, Measuring respiratory movement, Wearable strain sensor
\end{abstract}

(This article was submitted Nov. 18, 2017, and was accepted Jan. 23, 2018)

\section{INTRODUCTION}

Among all means to measure and follow changes in pulmonary function, the most frequently used means is to measure the volumes and airflow of the vital capacity by a spirometer. However, it is also important to measure the chest-abdomen expansion for exploring the rootcauses of the impaired pulmonary function, such as the dyspnea or rheumatic diseases, physical conditions after the thoracic and abdominal surgery, or decreased exercise tolerance ${ }^{1-3}$, for which, various techniques can be used.

For example, such sophisticated instruments as inductive or opto-electronic plethysmography, computed tomography or video systems have been used in clinical practices ${ }^{4,5}$. However, these instruments are not suitable for general clinical practices due to their high cost. Therefore, some new devices with low cost have been developed, such as the respiratory movement measuring instrument (RMMI), breathing movement measuring device (BMMD) and 3D motion analysis system etc. ${ }^{4-7)}$, but their application needs special experimental environment or to be installed in a complex setting.

A simple and practical method is using a measuring tape to assess the mobility of the chest-abdomen wall ${ }^{4,7,8)}$. However, this method is unable to indicate the best body spot for detecting the correlation of the data obtained by the tape to that

*Corresponding author. Haijuan Liu (E-mail: liuhaijuan0813@sina.com)

(C2018 The Society of Physical Therapy Science. Published by IPEC Inc.

(c) (1) $\odot$ This is an open-access article distributed under the terms of the Creative Commons Attribution Non-Commercial No Deriva-

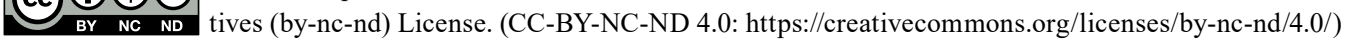


Table 1. All male participants baseline characteristics $(\mathrm{n}=30)$

\begin{tabular}{lc}
\hline & Mean $\pm \mathrm{SD}$ \\
\hline Age $(\mathrm{yrs})$ & $30.1 \pm 5.3$ \\
Height $(\mathrm{cm})$ & $172.9 \pm 5.6$ \\
Weight $(\mathrm{kg})$ & $76.0 \pm 17.5$ \\
BMI $\left(\mathrm{kg} / \mathrm{m}^{2}\right)$ & $26.0 \pm 4.7$ \\
\hline BMI: body mass index.
\end{tabular}

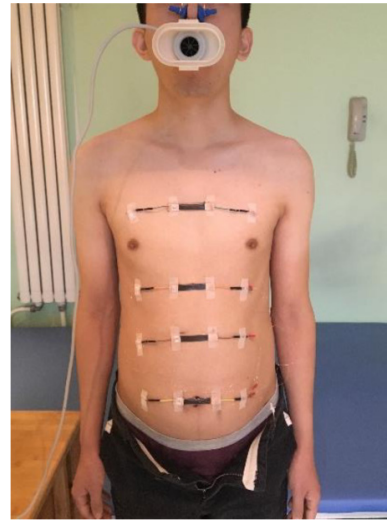

Fig. 1. Respiration measurement using wearable strain sensor (WSS) and spirometer.

obtained by the spirometer.

This study was conducted to explore the correlation of the data obtained by a newly developed wearable strain sensor (WSS) to the vital capacity data obtained by the spirometer. The purpose is to find the best body spots on the chest and abdomen wall to obtain the correlated indicators to the vital capacity.

\section{SUBJECTS AND METHODS}

This research was carried out at Physical Therapy Department in China Rehabilitation Research Center. Thirty healthy male staff of the center served as the participants, whose characteristics were presented in Table 1. The physical criteria for the participants were without a history of respiratory, circulatory, or neurological disorders. All participants gave written informed consent before taking part in this study. The Ethic Committees of International University of Health and Welfare (No.16-Io-238) and China Rehabilitation Research Center (CRRC-IEC-RF-SC-005-01) approved the study protocol.

The measurement of the vital capacity was performed from the maximal end of inspiration to the maximal end of expiration done by a spirometer (Pivot Flow 300, YiAn Technology Co. Ltd., China). A wearable strain sensor device (WSS) was used which comprises four sensors connected each other in parallel, each with a length of $3.5 \mathrm{~cm}$. The four sensors with medical adhesive tape were stuck to the chest-abdomen wall of each participant for monitoring its movement and expansion. The output of the sensors was connected to a circuit board, which was also stuck to the chest-abdomen wall. The circuit board received the sensor signals and transferred the signals to a computer through the bluetooth ${ }^{9}$. The monitored data are processed by a software (MATLAB Version 7.11.0.584 (R2010b), License Number: 161051), and the workable strain ranges of sensors were calculated by a spreadsheet software (Microsoft Excel, USA).

Four strain sensors were stuck respectively to four body spots, i.e. the axilla, xiphoid process, 10th rib and umbilicus of each of the 30 participants. It was required to wrap up the mouthpiece of the spirometer while using the nose clip, and to perform the chest abdominal breathing pattern movements with the shirts off and pants loosed in standing posture, the participants have been told not to move their trunk and shoulders during the measuring period ${ }^{9}$ ), as illustrated in Fig. 1. The breathing range was supposed to be from the maximal end of inspiration to the maximal end of expiration. The differences between the two maximal ends were recorded by the WSS and spirometer respectively. While a participant was breathing each time, the respiratory movement data were collected by the four parallel sensors and the vital capacity data were recorded by the spirometer.

The demographic data of the participants were expressed as means \pm SD (standard deviation). The correlation analysis on the specific Pearsons was conducted to find the correlation of the data obtained respectively by the WSS and spirometer during the breathing movements at the four body spots. All data were analyzed using the IBM SPSS statistics software version 24.0 for Windows, and the values of less than 0.05 were statistically significant level.

\section{RESULTS}

All participants baseline characteristics of anthropometry and vital capacity were shown in Table 1 . The raw data of the WSS compared by the spirometer for measuring breathing movement on axilla, xiphoid process, 10th rib and umbilicus respectively were presented in Table 2 . The correlation of the mobility data at the four body spots to the vital capacity data were calculated for each level by means of Pearson's correlation coefficient in Table 3, which showed that the values at each body spot were positive significant correlations and the highest value was at the 10th rib. 
Table 2. The raw data (Mean \pm SD) of the WSS compared by spirometer for measuring breathing movement at the four body spots

\begin{tabular}{cccccc}
\hline & $\begin{array}{c}\text { Spirometer } \\
(\mathrm{l})\end{array}$ & $\begin{array}{c}\text { Axilla } \\
(\mathrm{cm})\end{array}$ & $\begin{array}{c}\text { Xiphoid process } \\
(\mathrm{cm})\end{array}$ & $\begin{array}{c}\text { 10th rib } \\
(\mathrm{cm})\end{array}$ & $\begin{array}{c}\text { Umbilicus } \\
(\mathrm{cm})\end{array}$ \\
\hline Raw data & $3.61 \pm 0.51$ & $0.23 \pm 0.03$ & $0.23 \pm 0.04$ & $0.43 \pm 0.08$ & $0.28 \pm 0.06$ \\
\hline
\end{tabular}

WSS: wearable strain sensor.

Table 3. The correlation of the WSS data at the four body spots to the vital capacity data were calculated for each level

\begin{tabular}{lcccc}
\hline & Axilla & Xiphoid process & 10th rib & Umbilicus \\
\hline Correlation r-value & $0.676^{* *}$ & $0.631^{* *}$ & $0.824^{* *}$ & $0.715^{* *}$ \\
\hline \multicolumn{2}{l}{ WSS: wearable strain sensor. } & &
\end{tabular}

${ }^{*} \mathrm{p}<0.05,{ }^{* *} \mathrm{p}<0.01$ was significant correlation at 0.01 level (bilateral).

\section{DISCUSSION}

The results from this study tell us that there was a positive significant correlation $(p<0.01)$ between the mobility of the chest and abdomen and vital capacity at the four body spots. Furthermore, the 10th rib with a highest value is the best body spot to detect the correlation to the vital capacity. All of the results were satisfying.

Our preliminary study verified that the stretching length of each wearable strain sensor, i.e. $5 \%$ of axilla circumference $(5 \% \mathrm{AC})$ was selected as the longest length for measuring breathing, and the original length of $3.5 \mathrm{~cm}$ can be used. In this research, if only $5 \% \mathrm{AC}$ continues to be used, this is not obviously objective. Because $5 \% \mathrm{AC}$ is not the longest circumference of the chest and abdomen for the four body spots in this sample size, most of the participants had longer abdomen circumferences than that of their chest. In order to collect more accurate results, $5 \%$ of each body spot circumference was used. Thus, all of the findings were convincing.

According to the Asian standards of the World Health Organization (WHO) regulations, if BMI is in the range from 25.0 to 29.9 , then it is to be defined as being obese $\left.{ }^{10}\right)$. The participants in this test with BMI mean $(26.0 \pm 4.7)$ belong obesity group, but their 10th rib with the highest correlation value $(0.86)$ during respiratory movement were consistent with reports of both Carla et $\mathrm{al}^{7}$ ). Meyer suggested that a correlation coefficient $\mathrm{r} \geq 0.8$ means a high correlation, $\mathrm{r}=0.6-0.8$ means a good correlation, $r=0.4-0.6$ means a moderate correlation, and $r \leq 0.4$ means a poor correlation ${ }^{11)}$. Therefore, the 10th rib is the most significant body spot to explore the correlation to the vital capacity. The correlation values of the chest were distinctly lower than that of the abdomen during the breathing movements. There are two reasons for that as follows: 1 . To perform the breathing movement from the maximal end of inspiration to the maximal end of expiration in standing posture, the abdominal muscles press the abdominal content upwards to decrease the lung volume, the internal intercostals lower and decrease the rib cage $^{12-15)}$. During the maximal expiration in this test, the vital capacity was collected by the spirometer without any interferences, but the mobility variation of the rib cage was measured by the WSS, which would be increased due to the shoulders adduction. In other words, the smaller the range of the rib cage is, the greater the differences between the two maximal ends of respirations on axilla and xiphoid process are. 2. There is another suspicion, that is, the higher the value of the vital capacity data obtained by the spirometer is, the lower the respiratory value data obtained by the WSS is. The explanation for this is that the existence of differences in individual physiological structures leads to a greater vital capacity, meanwhile the mobility of the chest is not monitored during the breathing movements. Or abdomen breathing is dominant as a factor among the male participants ${ }^{13)}$. Based on the above analysis, the 10th rib is the best measuring spot compared with the other three spots. Monica et al. found that the mobility of the rib cage is smaller at the lower thoracic level of the xiphoid process than that at the level above the 4th rib. This result would be explicating that the correlation at xiphoid process is lower than that at axilla in this test ${ }^{4}$. Several limitations in this study should be considered: Firstly, the participants among the obesity group served as a disturbance factor that may increase errors; Secondly, the measured data in standing posture may be unstable during the breathing movements, because of that the participants would move their shoulders, which would impact the chest movement, though they have been told not to move their trunk during the measuring period; Thirdly, there was a random error when the strain sensors were placed at $5 \%$ of each body spot circumference, because some of the sensors were placed not so precisely.

The awareness of the movement correlation between the chest and abdomen is very important in future research, because it can interpret the results of different treatment interventions or changes in range of motion. Although the spirometers used worldwide have such advantages as high reliability, validity and sensitivity, and easy to handle ${ }^{16}$, in many clinical tests when they are used to evaluate the effects of different breathing exercises of changes or to explore the improving dynamic ranges of the breathing movements at different body spots, the measuring outcome is not sufficient to make a conclusion. Therefore, the method is not satisfactory. In this study, the WSS with high sensitivity and accuracy, used to find the correlation to the data 
obtained by spirometer, presented certain advantages such as lower cost, easy application, and specific body spot analysis. To detect voluntary mobility of the chest and abdomen during the breathing movements by the WSS seems to reflect better than the vital capacity. These findings could possibly be useful for evaluating the effects of breathing exercises at different body spots of a patient with a restricted lung capacity, such as the rheumatic patients, the senior people, and the postoperative patients. Therefore, in the future studies, the further research should pay more attention to participants with different disease in the chest and abdomen.

In summary, there was a correlation between the mobility data of the chest and abdomen obtained by the WSS and the vital capacity data obtained by the spirometer, for which, the 10th rib is the best body spot to detect the positive significant correlation. Therefore, we can infer the pulmonary function according to the mobility of the chest and abdomen in the future.

\section{Conflict of interest}

There are no conflicts of interest.

\section{REFERENCES}

1) Moll JM, Wright V: An objective clinical study of chest expansion. Ann Rheum Dis, 1972, 31: 1-8. [Medline] [CrossRef]

2) Finsback C, Mannerkorpi K: Spinal and thoracic mobility age-related reference values for healthy men and women. Nordisk Fysioterapi, 2005 , 9:1 136-143.

3) Malaguti C, Rondelli RR, de Souza LM, et al.: Reliability of chest wall mobility and its correlation with pulmonary function in patients with chronic obstructive pulmonary disease. Respir Care, 2009, 54: 1703-1711. [Medline]

4) Fiamma MN, Samara Z, Baconnier P, et al.: Respiratory inductive plethysmography to assess respiratory variability and complexity in humans. Respir Physiol Neurobiol, 2007, 156: 234-239. [Medline] [CrossRef]

5) Ferrigno G, Pedotti A: ELITE: a digital dedicated hardware system for movement analysis via real-time TV signal processing. IEEE Trans Biomed Eng, 1985, 32: 943-950. [Medline] [CrossRef]

6) Olsén MF, Romberg K: Reliability of the respiratory movement measuring instrument, RMMI. Clin Physiol Funct Imaging, 2010, 30: 349-353. [Medline]

7) Shobo A, Kakizaki K: Effects of two sitting positions on chest volume. Rigaku Ryohougaku, 2015, 30: 499-502 (In Japanese).

8) Fregonezi GA, Resqueti VR, Güell R, et al.: Effects of 8-week, interval-based inspiratory muscle training and breathing retraining in patients with generalized myasthenia gravis. Chest, 2005, 128: 1524-1530. [Medline] [CrossRef]

9) Wei H, Chen S, Zhou B, et al.: Highly sensitive and transparent strain sensor based on thin elastomer film. Electron Device Lett, 2016, 37: 667-670. [CrossRef]

10) WHO: Obesity: preventing and managing the global epidemic. Report of a WHO Consultation. WHO Technical report series 894 . Geneva: World Health Organization, 2000 .

11) Meyer CR: Measurement in physical education. New York: Ronald Press, 1979.

12) Lumb AB: Nunn's applied respiratory physiology. Oxford: Butterworth-Heinemann, 2000.

13) Hlastala MP, Berger AJ: Physiology of respiration. Oxford: Oxford University Press, 2001

14) Olseni L, Wollmer P: Sjukgymnastik vid nedsatt lungfunk-tion. Lund: Studentlitteratur, 2003.

15) Quanjer PH, Tammeling GJ, Cotes JE, et al.: Lung volumes and forced ventilatory flows. Eur Respir J, 1993, 6: 5-40. [Medline] [CrossRef]

16) Pasquina P, Tramèr MR, Walder B: Prophylactic respiratory physiotherapy after cardiac surgery: systematic review. BMJ, 2003, 327: 1379. [Medline] [CrossRef] 